\title{
Physicochemical and sensory properties of yogurts containing sacha inchi (Plukenetia volubilis L.) seeds and $\beta$-glucans from Ganoderma lucidum
}

\author{
Ana-Milena Vanegas-Azuero and Luis-Felipe Gutiérrez ${ }^{1}$ \\ Instituto de Ciencia y Tecnología de Alimentos (ICTA), Universidad Nacional de Colombia Sede Bogotá, Bogotá DC, Colombia, 111321
}

\begin{abstract}
Dairy products have been widely used for adding various biomolecules with the aim of improving their functional properties and health benefits. In this study, the physicochemical properties and sensory acceptance of yogurts enriched with sacha inchi (Plukenetia volubilis) seeds (SIS) and $\beta$-glucans from Ganoderma lucidum (BGGL) were investigated. The angiotensin-converting enzyme-inhibitory activity of some yogurt samples was also evaluated. Yogurts were produced from reconstituted skim milk powder, and SIS (4\% wt/wt) and BGGL were added at different concentrations (0-1.5\% $\mathrm{wt} / \mathrm{wt})$. The fermentation kinetics were not affected by the enrichment process. The addition of SIS and BGGL significantly increased the contents of protein, fat, carbohydrates, ash, total solids, aspartic acid, serine, arginine, glycine, threonine, tyrosine, and alanine. $\alpha$-Linolenic (49.3\%) and linoleic (32.2\%) acids were the main fatty acids found in the enriched samples, whose values were about 50 - and 25-fold higher than those of the control yogurt. The textural parameters (firmness, consistency, cohesiveness, and index of viscosity) of the enriched yogurts were significantly lower than those of the control samples during the whole storage period. All enriched yogurts showed a sensorial acceptance higher than $70 \%$ by untrained panelists. The angiotensin-converting enzyme-inhibitory activity of some selected yogurt samples ranged between 36 and $59 \%$. These results indicate that SIS and BGGL could be used as natural ingredients for improving the nutritional value of yogurt and fermented milks.
\end{abstract}

Key words: yogurt, sacha inchi, $\beta$-glucan, Ganoderma lucidum

\section{INTRODUCTION}

Yogurt is recognized as a healthy food throughout the world due to its beneficial effects on human health.

Received May 26, 2017.

Accepted September 14, 2017.

${ }^{1}$ Corresponding author: lfgutierreza@unal.edu.co
Although it contains natural compounds of high nutritional value, such as proteins, peptides, vitamins (principally $\mathrm{B}_{12}$, riboflavin, and $\mathrm{D}$ ), and minerals (mainly Ca, P, I, and K), there is great interest in the enrichment of this dairy product to further improve its nutritional value and health benefits because it is considered a foodstuff for daily consumption (Singh et al., 2012; Williams et al., 2015). Nowadays, probiotics are the main bioactive compounds added to yogurt. However, efforts are being made to enrich yogurt with other functional ingredients originating from dairy and nondairy sources. Among them, different types of fibers, phytosterols, polyphenols, stanols, peptides, isoflavones, $\beta$-glucans from various sources, essential fatty acids, whey protein concentrate, minerals, and vitamins have been investigated (Özer and Kirmaci, 2010). It is worth mentioning that the incorporation of any functional ingredient into a dairy product such as yogurt will have an effect on its final cost. Consequently, the dairy industry needs to establish cost-effective strategies and processes to achieve the development of functional products at the lowest cost possible, even if these products could have the potential to mitigate some diseases, promote health, and reduce health care costs.

Essential fatty acids (from the families of n-3 and n-6) have gained special attention as functional ingredients because of their wide range of health benefits, including brain development and reduced risk of cardiovascular diseases, certain types of cancer, and inflammatory diseases (Simopoulos, 2002). Because milk is relatively poor in essential fatty acids, the development of dairy products rich in essential fatty acids could contribute to increasing the intake of these biomolecules in the population. Fish oils are the main natural sources of long-chain n-3 fatty acids. However, their incorporation into fermented milks may confer negative effects on their texture, sensory properties, and shelf life (Isanga and Zhang, 2009; Sabeena Farvin et al., 2010). The addition of oils rich in n-3 in the form of microcapsules (Martín-Diana et al., 2004; Sabeena Farvin et al., 2010; Tamjidi et al., 2012), emulsions (Chee et al., 2005) and nanoemulsions (Lane et al., 2014; Boye, 2015) has been successfully used to circumvent these problems. 
The enrichment with short-chain n-3 fatty acids from vegetable oils (Dal Bello et al., 2015), seeds, nuts, and fruit pulps (do Espírito Santo et al., 2010; OzturkogluBudak et al., 2016) has also been investigated, although from a nutritional and functional point of view their effects are not exactly the same as those of the longchain n-3 fatty acids contained in fish oils.

$\beta$-Glucans are polysaccharides of D-glucose monomers linked through $\beta$-glycosidic bonds, present in cereal crops (especially barley and oats) and some mushrooms. These compounds are considered bioactive compounds due to their biological activities, including anti-cancer, anti-inflammatory, and immune-modulating properties (Zhu et al., 2016). Moreover, $\beta$-glucans are among the main fractions of the dietary fiber of some grains, such as oats and barley (Ciron et al., 2010). Various studies suggest that the addition of $\beta$-glucans at concentrations up to $0.5 \%$ to fermented milks has no negative effects on their quality, whereas the enrichment at higher concentration levels may reduce the fermentation rate, increase the viscosity, and lead to syneresis due to thermodynamic incompatibility between the $\beta$-glucans and the milk proteins (Singh et al., 2012; Lazaridou et al., 2014; Sharafbafi et al., 2015).

The aim of this work was to evaluate the physicochemical properties and the sensory acceptance of yogurts enriched with sacha inchi seeds (SIS), which are rich source of n-3 and n-6, tocopherols, phytosteroles, phenolics compounds, protein of high nutritional value, and dietary fiber; Gutiérrez et al., 2011; Chirinos et al., 2013) and $\beta$-glucans from Ganoderma lucidum (BGGL; Ganogen, Progal-BT, Medellín, Colombia), a commercial ingredient obtained by submerged cultivation of Ganoderma lucidum, an edible mushroom used as a traditional medicine, pharmaceutical, and nutraceutical agent in various Asian countries for the treatment of several human diseases, including hypertension, hypercholesterolemia, and various types of cancer (Bishop et al., 2015). Moreover, because milk fermentation by lactic acid bacteria has shown to release angiotensin-converting enzyme (ACE)-inhibitory peptides, the ACE-inhibitory activity of some selected yogurt samples was also investigated.

\section{MATERIALS AND METHODS}

\section{Materials}

The SIS were kindly supplied by a local grower from Fusagasugá (Cundinamarca, Colombia). The seeds were manually selected by discarding those presenting physical damage. Then, they were vacuum packaged in polyethylene bags and stored at $-40^{\circ} \mathrm{C}$ until use. Com- mercial $\beta$-glucans (Ganogen), produced by submerged cultivation of Ganoderma lucidum, were kindly supplied by Progal-BT (Medellín, Colombia). The starter culture Yomix 205 LYO (Streptococcus thermophilus, Lactobacillus delbrueckii ssp. bulgaricus, Lactobacillus acidophilus, and Bifidobacterium lactis) was generously provided by DuPont Colombia (Bogotá). The skim milk powder $(\sim 2 \mathrm{~g}$ of fat/L) and sucrose were purchased in local markets. All reagents and standards used in the analytical determinations were of analytical grade and purchased from Sigma-Aldrich (St. Louis, MO).

\section{Methods}

The protein, ash, moisture, and fat contents of the SIS and BGGL were determined using methods 950.36, 923.03, 935.29, and 922.06, respectively (AOAC International, 2012). The content of total carbohydrates was calculated by difference. The fatty acid composition of the SIS was determined by GC as described by Gutiérrez and Belkacemi (2008).

The $\beta$-glucans of the commercial Ganogen (BGGL) were extracted according to the method proposed by Dong et al. (2012) and analyzed in terms of their glycosidic composition by means of size exclusion chromatography HPLC (Superose 12-column $10 \times 300 \mathrm{~mm}$ evaporative light scattering detector; GE, Amersham, UK), and GC-MS analyses of their per- $O$-trimethylsilyl derivatives [Agilent (Santa Clara, CA) 7890A GC interfaced to a $5975 \mathrm{C}$ Mass Selective Detector using an Agilent DB-1 fused silica capillary column $(30 \mathrm{~m} \times 0.25$ $\mathrm{mm}$ i.d.)], following the procedures recommended by Merkle and Poppe (1994) and York et al. (1985).

Thermogravimetric analyses (TGA) were performed using a TGA 1 (Mettler-Toledo, Columbus, OH). Samples of $5 \mathrm{mg}$ of BGGL were weighed in an aluminum pan and heated at $10^{\circ} \mathrm{C} / \mathrm{min}$ to $550^{\circ} \mathrm{C}$ (Kumar, 2010). Data were analyzed using thermal analysis software (STARe Evaluation; Mettler-Toledo).

Transform infrared (FT-IR) spectra were recorded in transmission mode on a Nicolet iS10 FT-IR spectrometer (Thermo Scientific, Waltham, MA) in the range of 400 to $4,000 \mathrm{~cm}^{-1}$ by the coaddition of 20 scans at a resolution of $8 \mathrm{~cm}^{-1}$. The FT-IR analyses were carried out at room temperature using potassium bromide pellets containing about $0.5 \%$ of the BGGL samples (Gutiérrez et al., 2012).

\section{SIS Conditioning}

The SIS were hand shelled, washed with tap water, and then roasted at $160 \pm 5^{\circ} \mathrm{C}$ in an oven for about 2 $\mathrm{h}$ until the bitter taste disappeared. The roasted seeds 
were ground using a corn mill and separated by size using sieves to select those with a particle size of about $3 \mathrm{~mm}$.

\section{Starter Culture Activation}

The freeze-dried starter culture Yomix 205 was activated by dissolving $1 \mathrm{~g}$ in sterilized skim milk and incubating at $43 \pm 1^{\circ} \mathrm{C}$ for $2 \mathrm{~h}$. This activated culture was used for the inoculation of the yogurt samples.

\section{Yogurt Manufacture}

Skim milk powder was reconstituted to $13 \%$ (wt/ wt) in distilled water and divided into 5 milk samples. The ground SIS ( $4 \% \mathrm{wt} / \mathrm{wt}$; particle size of $\sim 3.0 \mathrm{~mm}$ ), sucrose $(7.5 \% \mathrm{wt} / \mathrm{wt})$, and BGGL (particle size ranging between 150 and $500 \mu \mathrm{m} ; 0,0.5,1.0$, and $1.5 \% \mathrm{wt} /$ wt, respectively) were added to 4 samples (T1, T2, T3, and T4, respectively). The fifth milk sample was used as a control. These milk bases were poured into 1-L Duran laboratory glass bottles (Sigma-Aldrich, St. Louis, MO) and pasteurized at $85 \pm 2^{\circ} \mathrm{C}$ for $30 \mathrm{~min}$. After cooling to $43 \pm 1^{\circ} \mathrm{C}$ in an ice bath, they were inoculated with the activated starter culture $(8 \mathrm{~mL} / \mathrm{L})$ and incubated at $43 \pm 1^{\circ} \mathrm{C}$ for about $5 \mathrm{~h}$ until a pH value of $4.6 \pm 0.05$ was attained. After incubation, the yogurt samples were cooled, gently stirred, divided into 250-mL portions, and stored at $4 \pm 1^{\circ} \mathrm{C}$.

\section{Proximate Composition Analysis}

Proximal analyses of the yogurt samples were performed on d 1 of refrigerated storage. Moisture, ash, and protein were determined according to AOAC methods (James, 1995). The fat content was determined as described by Osorio et al. (2011) using chloroformmethanol 2:1 (vol/vol) as a solvent. The CP was determined by the Kjeldahl method using a conversion factor of 6.38. Total carbohydrates were calculated by difference. The calorific values were calculated according to the following equation (Isanga and Zhang, 2009):

$\mathrm{EV}=(\mathrm{kJ} / 100 \mathrm{~g})=(17 \times \mathrm{C})+(17 \times \mathrm{P})+(37 \times \mathrm{F})$,

where $\mathrm{EV}=$ energy value of the yogurt sample and $\mathrm{C}, \mathrm{P}$, and $\mathrm{F}=$ carbohydrate, protein, and fat contents (\%), respectively.

\section{Fatty Acid Composition}

The fatty acid composition of the yogurt samples was determined by GC as indicated by Gutiérrez and Belka- cemi (2008). The fatty acid methyl esters (FAME), obtained by alkaline methylation with sodium methoxide in methanol 0.5 $M$ (Sigma-Aldrich), were analyzed on an Agilent model 7890A gas chromatograph. The oven temperature was programmed as follows: from $60^{\circ} \mathrm{C}$ (isothermal for $1 \mathrm{~min}$ ) to $190^{\circ} \mathrm{C}$ at $20^{\circ} \mathrm{C} / \mathrm{min}$, and an isothermal period of $30 \mathrm{~min}$ at $190^{\circ} \mathrm{C}$. Helium was used as a carrier gas at $1.5 \mathrm{~mL} / \mathrm{min}$. The GC separation peaks were performed on an HP-88 $(100 \mathrm{~m} \times 0.25 \mathrm{~mm}$ i.d. $\times 0.20 \mu \mathrm{m}$ film thickness; Agilent J\&W GC Columns, Santa Clara, CA). The fatty acids were identified by comparing their retention times with those of the FAME standards (FAME Mix C4-C24) purchased from Sigma-Aldrich. Peaks were integrated using the Agilent ChemStation software. Measurements were performed in triplicate on d 1, 10, and 20.

\section{Index of Atherogenicity}

The index of atherogenicity (IA) of the yogurt samples was calculated as described by Osorio et al. (2011) using the following equation:

$$
\mathrm{IA}=\frac{\mathrm{C} 12: 0+4 \times \mathrm{C} 14: 0+\mathrm{C} 16: 0}{\sum \mathrm{UFA}} .
$$

\section{Water Holding Capacity}

The water holding capacity (WHC) of the yogurt samples was determined as proposed by Harte et al. (2003), with slight modifications. The yogurt samples were centrifuged at $8,000 \times g$ and $4^{\circ} \mathrm{C}$ for 15 min using a refrigerated centrifuge (Heraeus Multifuge X3R; Thermo Scientific). The WHC was calculated as follows:

$$
\operatorname{WHC}(\%)=100 \times\left(1-\frac{W_{1}}{W_{2}}\right),
$$

where $W_{1}=$ weight of whey after centrifugation and $W_{2}=$ weight of the yogurt sample. Measurements were performed in triplicate on d 1, 10, and 20 .

\section{Susceptibility to Syneresis}

The susceptibility to syneresis (STS) of the yogurt samples was determined as proposed by Isanga and Zhang (2009) with some modifications. The yogurt samples $(70 \mathrm{~mL})$ were poured into filtration funnels with qualitative filter paper (Whatman grade 4; Sigma-Aldrich). The samples were allowed to drain 
under gravity for $6 \mathrm{~h}$, and the released whey volume was measured using a graduated cylinder. The STS was calculated using the following equation:

$$
\operatorname{STS}(\%)=100 \times\left(\frac{V_{1}}{V_{2}}\right),
$$

where $V_{1}=$ volume of the released whey after drainage and $V_{2}=$ volume of the yogurt sample. Measurements were performed in triplicate on d 1, 10, and 20 .

\section{Flow Behavior}

The flow behavior of the yogurt samples was evaluated using a rotational viscometer (Haake viscotester, Thermo Scientific) equipped with a sensor MV-DIN. The experiments were performed at $10 \pm 0.5^{\circ} \mathrm{C}$ in ascending (from 0.08 to $12.2 \mathrm{~s}^{-1}$ ) and descending (from 12.2 to $0.08 \mathrm{~s}^{-1}$ ) runs. The flow curves were adjusted to the power law model $\left(\sigma=K \dot{\gamma}^{n}\right)$, were $K$ is the consistency index and $n$ is the flow index. The fit correlation coefficients $\left(\mathrm{R}^{2}\right)$ were always higher than 0.95 . Measurements were performed in triplicate on $\mathrm{d} 1,10$, and 20. Taking into account that the annular space between the 2 cylinders of the viscometer is smaller than the mean particle size of the SIS contained in the yogurt samples, the SIS were removed from the samples using a 2-mm domestic sieve.

\section{Textural Parameters}

The texture of the yogurt samples was characterized by means of the back-extrusion (pseudocompression) method described by Ciron et al. (2010). The experiments were performed on a texture analyzer (TA.XT Plus Texture Analyzer; Stable Micro Systems, Godalming, UK) equipped with a 5-kg load cell. The yogurt samples were poured into acrylic containers (height $=$ $65 \mathrm{~mm}$, diameter $=50 \mathrm{~mm}$ ) immediately after removal from storage $\left(\sim 5^{\circ} \mathrm{C}\right)$ and analyzed using an extrusion disk (diameter $=40 \mathrm{~mm}$ ) operating at a constant speed of $1.0 \mathrm{~mm} / \mathrm{s}$ to a depth of $30 \mathrm{~mm}$. The compression was carried out one time using a trigger force of $10.0 \mathrm{~g}$. The force-time curves were recorded and the textural parameters were calculated using Texture Exponent 32 software (version 4.0.8.0; Stable Micro Systems). The textural parameters derived were firmness (maximum force during compression - i.e., rupture point of the gel; $\mathrm{g}_{\mathrm{f}}$ ), consistency (positive peak area within curve during extrusion thrust; $\mathbf{g}_{\mathrm{f}} \cdot \mathbf{s}$ ), cohesiveness (maximum compression force during probe return, which indicates the resistance to withdraw the extrusion disc being lifted; $\mathrm{g}_{\mathrm{f}}$ ), and index of viscosity (area within the negative region of the curve during probe return; $\mathrm{g}_{\mathrm{f}} \mathrm{s}$ ). Each sample was analyzed in triplicate on d 1, 10, and 20.

\section{Postacidification Measurements}

The postacidification of the yogurt samples was determined by measuring their $\mathrm{pH}$ value and titratable acidity (TA) during refrigerated storage. The $\mathrm{pH}$ value was determined at approximately $10^{\circ} \mathrm{C}$ using a digital portable $\mathrm{pH}$ meter (Orion Star A221; Thermo Scientific) equipped with an automatic temperature compensation. The TA was determined by titration with $0.1 \mathrm{~N} \mathrm{NaOH}$ and calculated as follows:

$$
\mathrm{TA}(\text { lactic acid } \%)=\frac{\mathrm{V}_{\mathrm{NaOH}} \times 0.1 \times 0.09}{\mathrm{~W}} \times 100,
$$

where $\mathrm{V}_{\mathrm{NaOH}}=$ volume of $\mathrm{NaOH} 0.1 \mathrm{~N}$ used to neutralize the lactic acid present in the sample and $\mathrm{W}=$ weight of the yogurt sample.

\section{Sensory Analysis}

Hedonic sensory tests were conducted by 53 untrained panelists consisting of staff and students of the Universidad Nacional de Colombia Sede Bogotá. The yogurt samples, served in 20-mL plastic cups at approximately $10^{\circ} \mathrm{C}$, were evaluated for overall acceptability on a 7-point hedonic scale, ranging from extremely dislike to extremely like. Water was provided between evaluations of samples for mouth rinsing. Samples were considered acceptable when the percentage of discrimination as "like" was higher than $60 \%$ (Meilgaard et al., 2006). All samples were evaluated in random order among panelists.

\section{AA Composition}

The AA composition of some selected yogurt samples was determined using the acid hydrolysis method reported by Jajić et al. (2013). The analyses were performed on an HPLC Elite LaChrom (Hitachi, Tokyo, Japan) equipped with a L-2300 thermostated column compartment, L-2100 binary pump, L-2200 standard autosampler, L-2480 fluorescence detector, and Luna C18 column $(250 \mathrm{~mm} \times 4.6 \mathrm{~mm}$ i.d., $5 \mu \mathrm{m}$ particle size; Phenomenex, Torrance, CA). The following solutions were used as mobile phase: solution A, sodium phosphate dibasic $0.04 M$ adjusted to $\mathrm{pH} 7.8$ with $\mathrm{HCl}$; solution B, acetonitrile-methanol-water (45:45:10, vol $\%$ ). The hydrolyzed samples were derivatized with $o-$ 
phthaldialdehyde and 9-fluorenylmethyl chloroformate and injected into the column at $40^{\circ} \mathrm{C}$, with detection at 338 and $262 \mathrm{~nm}$. The separation was performed at a flow rate of $2 \mathrm{~mL} / \mathrm{min}$ using the following solvent gradient (vol \%): 0 min, 0\% B; $1.9 \mathrm{~min}, 0 \% \mathrm{~B} ; 18.1 \mathrm{~min}, 57 \%$ B; 18.6 min, $100 \%$ B; 22.3 min, $100 \%$ B; $23.2 \mathrm{~min}, 0 \%$ $\mathrm{B}$; and $26 \mathrm{~min}, 0 \% \mathrm{~B}$. Individual AA standards from Sigma-Aldrich were used for obtaining the calibration curves.

\section{ACE-Inhibitory Activity}

The ACE-inhibitory activity of some selected samples was determined as reported by Hernández-Ledesma et al. (2003). In brief, $110 \mu \mathrm{L}$ of substrate (hippurylhistidyl-leucine dissolved in a $\mathrm{pH} 8.3$ buffer with $0.3 \mathrm{M}$ $\mathrm{NaCl}$ ) were mixed with $25 \mu \mathrm{L}$ of ACE of rabbit lung (26 mU/mL; EC 3.4.15.1, Sigma-Aldrich) dissolved in glycerol at $50 \%$ and added to $15 \mu \mathrm{L}$ of whey yogurt. The solution was incubated at $37^{\circ} \mathrm{C}$ for $90 \mathrm{~min}$. The ACE activity was stopped by adding $110 \mu \mathrm{L}$ of $1 \mathrm{~N}$ $\mathrm{HCl}$. The hippuric acid formed in the enzymatic reaction was extracted with $1 \mathrm{~mL}$ of ethyl acetate. An aliquot of $750 \mu \mathrm{L}$ of the organic layer was taken and dried out in a block heater at $95^{\circ} \mathrm{C}$. The residue was dissolved in distilled water $(1 \mathrm{~mL})$, and the absorbance was measured at $228 \mathrm{~nm}$ using a Genesys $10 \mathrm{~S}$ UV-vis spectrophotometer (Thermo Scientific). A reaction solution was prepared in the same way by adding $15 \mu \mathrm{L}$ of distilled water instead of the whey sample. The reaction and sample blanks were prepared in the same way by adding the $\mathrm{HCl}$ solution before adding the enzyme. The determinations were carried out in triplicate. The ACE-inhibitory (I) activity (\%) was calculated as follows:

$$
\operatorname{ACE}-\mathrm{I} \operatorname{activity}(\%)=100 \times\left[1-\frac{\mathrm{C}-\mathrm{D}}{\mathrm{A}-\mathrm{B}}\right] \text {, }
$$

where $\mathrm{A}=$ absorbance in the presence of $\mathrm{ACE}, \mathrm{B}=\mathrm{ab}-$ sorbance of the reaction blank, $\mathrm{C}=$ absorbance in the presence of $\mathrm{ACE}$ and inhibitor, and $\mathrm{D}=$ absorbance of the sample blank.

\section{Experimental Design and Statistical Analysis}

The experiments were carried out following a randomized block design. The experimental units (2 L of yogurt) were divided into 3 homogeneous blocks and then randomly assigned to a treatment group. An ANOVA by the GLM procedure and mean comparisons by the least significant difference test were performed using SAS (version 9.4; SAS Institute Inc., Cary, NC).

\section{RESULTS AND DISCUSSION}

\section{Characterization of SIS and BGGL}

The SIS used in this study comprised fat (42\%), carbohydrates $(27.5 \%)$, protein $(25 \%)$, moisture $(3 \%)$, and ash (2.5\%), whereas their fatty acid composition was characterized by high values of $\alpha$-linolenic acid (ALA; 50.2\%), and linoleic acid (LA; 32.1\%) and minor amounts of palmitic (5.6\%), stearic (2.6\%), and oleic $(9.5 \%)$ acids. These results agree with those previously reported by Gutiérrez et al. (2011) and SanchezReinoso and Gutiérrez (2017).

The BGGL principally comprised carbohydrates $(93.5 \%)$, with lower amounts of moisture (4.3\%), protein $(2.0 \%)$, and ash $(0.2 \%)$. These results were in agreement with the technical data sheet furnished by the manufacturer. According to the size exclusion chromatography HPLC analyses, the main glycosyl residues found in BGGL were glucose $(93.1 \%)$, mannose $(4.2 \%)$, xylose $(1.4 \%)$, and galactose (1.1\%). Moreover, the GC-MS analyses of the per- $O$-trimethylsilyl derivatives indicated that more than $45 \%$ of the glycosyl residues were 3-linked glucopyranosyl, followed by 3,6-linked glucopyranosyl (20.3\%) and terminally linked glucopyranosyl $(20.1 \%)$ residues. These results are in agreement with the findings of Dong et al. (2012) for $\beta$-glucans isolated from Ganoderma lucidum. The linkage result also indicated the presence of other minor residues, such as t-Rhap, t-Fucp, t-Xylp, 3,4-Manp, and 6-Galp.

The TGA were carried out to evaluate the weight loss and the decomposition of BGGL as a function of temperature. As depicted in Figure 1, a weight loss peak occurred at about $120^{\circ} \mathrm{C}$, corresponding to the loss of approximately $5 \%$ water. This value was very close to that obtained in the proximate analysis $(4.3 \%)$. For higher temperatures (up to $200^{\circ} \mathrm{C}$ ), there was no appreciable weight loss. From this temperature the BGGL began to decompose, and their complete degradation was close to $350^{\circ} \mathrm{C}$. Similar TGA profiles were obtained recently for barley $\beta$-glucans (Kumar, 2010). These results suggest that BGGL do not decompose under the pasteurization conditions applied in this study.

A useful analytical technique for the identification of the characteristic organic groups of polysaccharides, especially $\mathrm{O}-\mathrm{H}, \mathrm{N}-\mathrm{H}$, and $\mathrm{C}=\mathrm{O}$, is FT-IR spectroscopy. The FT-IR spectra of BGGL in the range of 400 to $4,000 \mathrm{~cm}^{-1}$ are shown in Figure 2. As can be seen, the IR pattern of BGGL displayed a characteristic broad low-frequency absorption band centered at $3,425 \mathrm{~cm}^{-1}$ in the hydroxyl region $\left(3,000-4,000 \mathrm{~cm}^{-1}\right)$, which may be assigned to the stretching vibrations of $\mathrm{O}-\mathrm{H}$ in the constituent sugar residues and to the adsorbed water (Huang et al., 2011; Gutiérrez et al., 2012; Kan et al., 
2015). The small absorption band at around $2,923 \mathrm{~cm}^{-1}$ and the strong one observed at approximately 1,383 $\mathrm{cm}^{-1}$ are attributed to the stretching vibration of $\mathrm{C}-\mathrm{H}$ in the sugar ring (Huang et al., 2011; Kozarski et al., 2012). The presence of a small amount of proteins and $\mathrm{C}=\mathrm{C}$ aromatic groups is suggested by the absorption band found at $1,639 \mathrm{~cm}^{-1}$ (Kozarski et al., 2012). The fingerprint of polysaccharides generally ranges in the 1,200 to $850 \mathrm{~cm}^{-1}$ region, which normally presents ring vibrations overlapped with stretching vibrations of $(\mathrm{C}-\mathrm{OH})$ side groups and the $(\mathrm{C}-\mathrm{O}-\mathrm{C})$ glycosidic band vibrations (Kan et al., 2015). The absorption bands centered at approximately 1,157, 1,080, and $1,023 \mathrm{~cm}^{-1}$ evidenced the presence of $\beta$-glycosidic, glucosidic and C-O linkages, respectively (Kozarski et al., 2012). The small absorption band at around $930 \mathrm{~cm}^{-1}$ is attributable to $\alpha$ linkages, whereas that observed at $847 \mathrm{~cm}^{-1}$ may be assigned to the characteristic absorption band of $\beta$-glycosidic linkages between the sugar units (Huang et al., 2011; Kozarski et al., 2012; Kan et al., 2015).

\section{Fermentation Kinetics}

The fermentation kinetics of the different treatments evaluated in this study are presented in Figure 3. As can be observed, the enrichment of samples with SIS and BGGL did not significantly affect $(P>0.05)$ the fermentation kinetics. After $5 \mathrm{~h}$ of incubation, all the samples reached a $\mathrm{pH}$ value of about 4.6. This behavior was similar to that found in other studies, which demonstrated that the addition of oat $\beta$-glucan at 1.32 and $0.5 \%$ did not produce significant effects on the

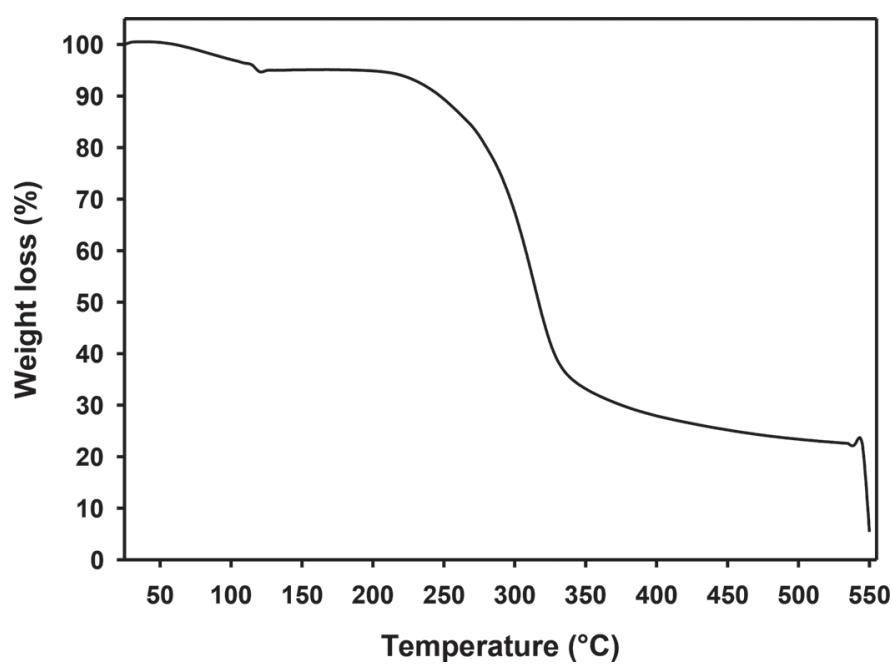

Figure 1. Thermogravimetric profile of $\beta$-glucans from Ganoderma lucidum.

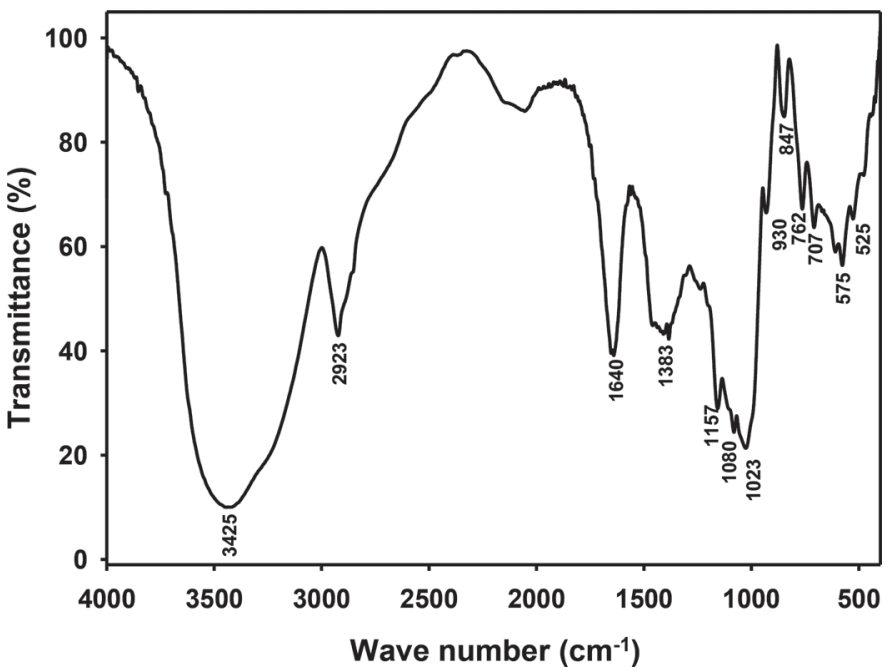

Figure 2. Transform infrared spectrum of $\beta$-glucans from Ganoderma lucidum.

acidification kinetics of milk fermented at $42^{\circ} \mathrm{C}$ with yogurt starter bacteria (Gee et al., 2007; Lazaridou et al., 2014).

\section{Proximate Composition Analysis}

Table 1 shows the proximate composition of yogurts enriched with SIS and BGGL in comparison with the control sample. As expected, the enrichment of yogurt with SIS and BGGL significantly increased $(P<0.05)$ the contents of protein, fat, carbohydrates, ash, and TS;

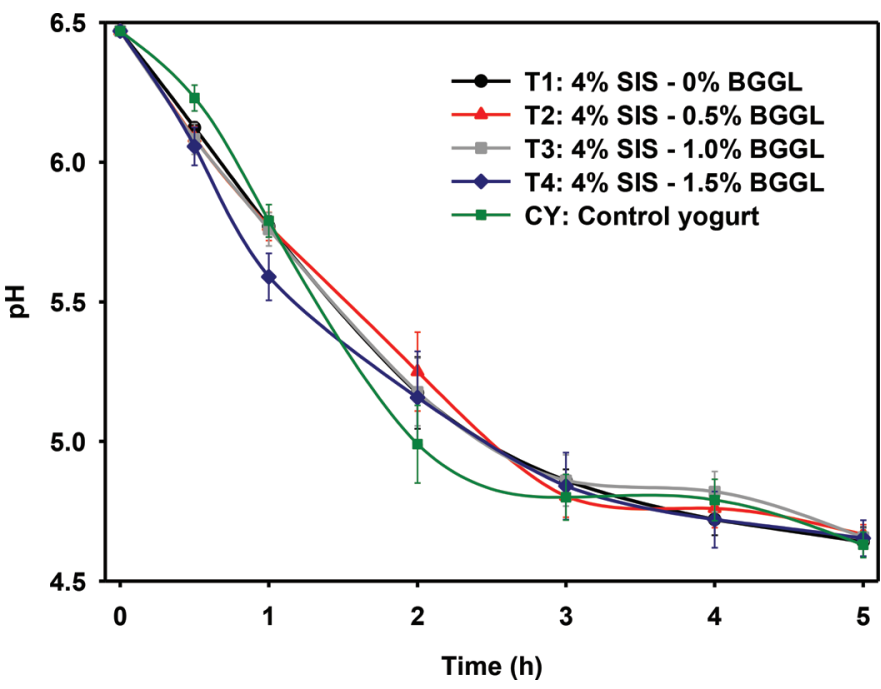

Figure 3. Fermentation kinetics of yogurts enriched with sacha inchi seeds (SIS) and $\beta$-glucans from Ganoderma lucidum (BGGL). Error bars indicate SD. Color version available online. 
Table 1. Proximate composition and fatty acid (FA) profile of yogurts enriched with sacha inchi seeds (SIS) and $\beta$-glucans from Ganoderma lucidum (BGGL) ${ }^{1}$

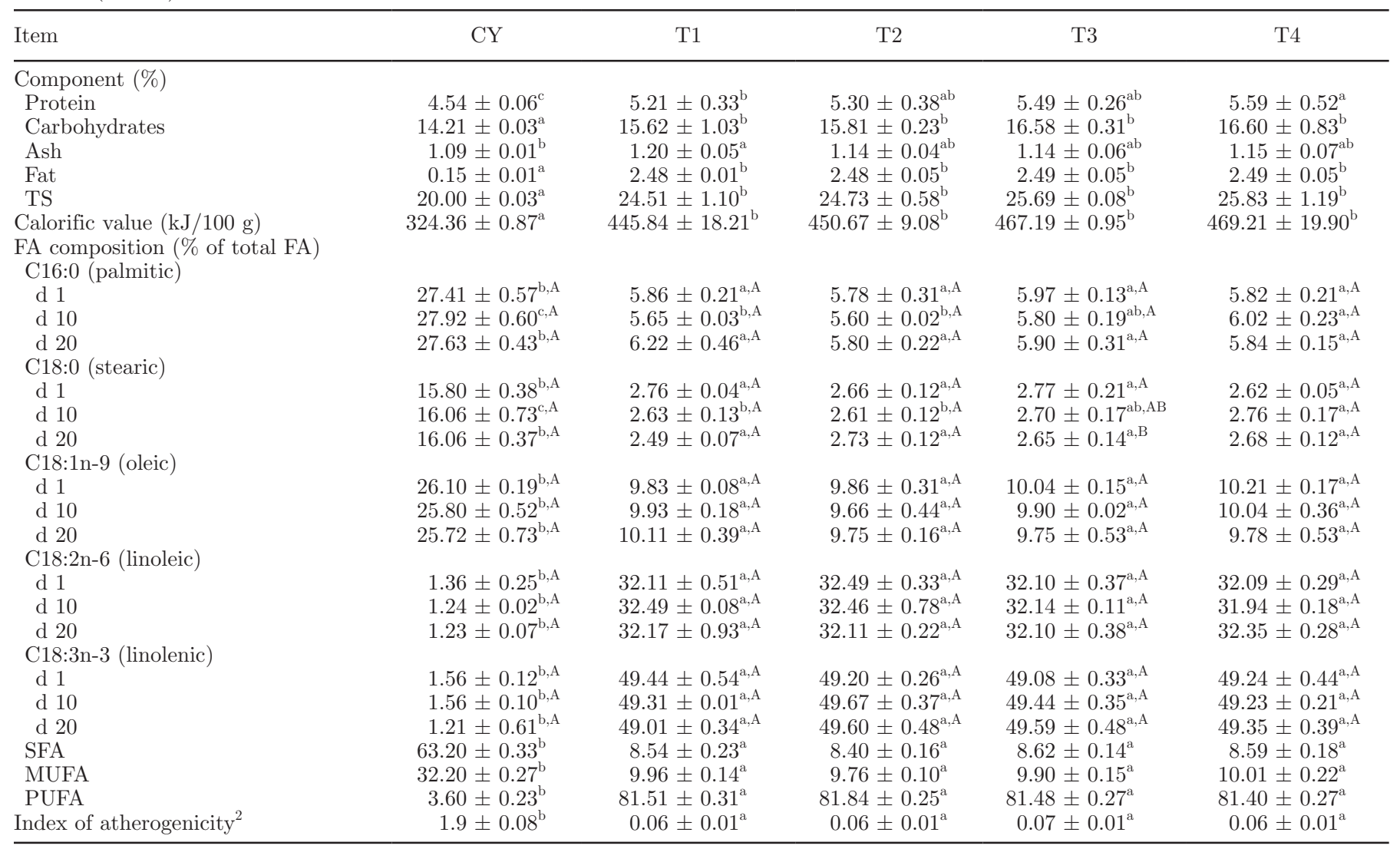

\footnotetext{
${ }^{\mathrm{a}-\mathrm{c}}$ Means in a row followed by the same superscript are not significantly different by LSD test at the $5 \%$ level.

${ }^{\mathrm{A}, \mathrm{B}}$ Means in a column followed by the same superscript are not significantly different by LSD test at the $5 \%$ level.

${ }^{1} \mathrm{CY}=$ control yogurt; $\mathrm{T} 1=$ yogurt enriched with $4 \%$ SIS and $0 \%$ BGGL; T2 = yogurt enriched with $4 \%$ SIS and $0.5 \%$ BGGL; T3 = yogurt enriched with $4 \%$ SIS and 1.0\% BGGL; T4 = yogurt enriched with $4 \%$ SIS and $1.5 \%$ BGGL.

${ }^{2}$ The index of atherogenicity was calculated as $(\mathrm{C} 12: \mathrm{D}+4 \times \mathrm{C} 14: 0+\mathrm{C} 16: 0) / \Sigma \mathrm{UFA}$.
}

the fat concentration was most influenced due to the high lipid content of the SIS. The contents of protein, carbohydrates, and TS of the enriched yogurt samples (T1 to T4) varied between 5.2 and 5.6, 15.6 and 16.6, and 24.5 and $25.8 \%$ (wt/wt), respectively, whereas the concentrations of fat and ash remained almost invariable due to the low concentration of these components in the BGGL.

In a recent study, Ozturkoglu-Budak et al. (2016) reported significant increases $(P<0.05)$ in the contents of protein, fat, and TS in yogurts fortified with dried nuts (hazelnut, pistachio, almond, and walnut) at $5 \%$ (wt/wt) after the fermentation process. Although the addition of the dried nuts used by the authors was higher than that used in this study ( 5 vs. $4 \%$ wt/wt), in comparison with the yogurts enriched with SIS and BGGL, the protein content was similar, whereas the concentrations of fat and TS were higher and lower, respectively.
It can be observed in Table 1 that yogurts enriched with SIS and BGGL displayed higher calorific values than the control samples $(P<0.05)$ because of their higher fat content; it is well known that fat stores more energy than carbohydrates and proteins (James, 1995). Nevertheless, there were no significant differences $(P>$ 0.05 ) between the calorific values of the enriched yogurt samples.

\section{Fatty Acid Composition}

The fatty acid composition of the yogurt samples is presented in Table 1. As can be noticed, the main fatty acids present in the yogurts enriched with SIS were ALA (49-50\%) and LA (32-33\%), whereas minor amounts of oleic $(9.0-10 \%)$, palmitic $(5-6 \%)$, and stearic $(2-3 \%)$ acids were also found. In contrast, the major fatty acids found in the control yogurts were palmitic (27-28\%), oleic (25-26\%), and stearic (15-16\%) acids. From these 
data, it can be observed that the contents of ALA and LA in yogurts enriched with SIS were about 50- and 25 -fold higher than those found in the control samples, whereas the concentrations of palmitic, stearic, and oleic acids were reduced 76,84 , and $63 \%$, respectively. Moreover, the IA of the yogurts enriched with SIS were much lower than those of the control samples (0.06 vs. 1.9). It is worth mentioning that the low ratio of LA/ ALA ( 0.66) displayed by the enriched yogurts is desirable for reducing the risk of many chronic diseases of high prevalence, such as cardiovascular disease, cancer, and inflammatory and autoimmune diseases (Simopoulos, 2002). The PUFA, MUFA, and SFA of the enriched yogurt samples were about 81 to $82 \%, 9$ to $10 \%$, and 8 to $9 \%$, respectively. In general, there were no significant variations $(P>0.05)$ in the fatty acid compositions of all yogurt samples during refrigerated storage, in agreement with other studies (do Espírito Santo et al., 2012). As mentioned previously, various strategies have been investigated for enriching yogurts with n- 3 and n- 6 fatty acids. By adding açai pulp to yogurt at $7 \%$ (wt/wt), do Espírito Santo et al. (2010) reported increases in the concentrations of ALA of between 1.12- and 1.69-fold, whereas increases in the concentrations of LA ranged from 3.58- to 3.99-fold. Recently, Ozturkoglu-Budak et al. (2016) reported that the fortification of yogurts $(3 \%$ wt/vol of fat) with ground dried nuts at $5 \%$ (wt/wt; hazelnut, pistachio, almond, and walnut) led to 1.8and 1.1-fold increases in the concentrations of LA and ALA, respectively, whereas the contents of palmitic, stearic, and oleic acids were not significantly affected. The results obtained in this study indicate that SIS are quite effective for reaching high concentrations of ALA and LA in dairy products such as yogurt.

\section{WHC and STS}

Syneresis is an important attribute in determining the quality of yogurt and fermented milks. It occurs in the whey separation during storage due to the shrinkage of the casein gel, thus becoming visible as surface whey and negatively affecting consumer perception (Lee and Lucey, 2010). Measurement of WHC and STS is the most common method for estimating the syneresis of fermented milks. Table 2 presents the WHC and STS of the yogurt samples during storage. As can be observed, the control samples showed lower WHC than the enriched yogurts $(P<0.05)$ during the whole period of

Table 2. Physicochemical properties of yogurts enriched with sacha inchi seeds (SIS) and $\beta$-glucans from Ganoderma lucidum (BGGL) during storage

\begin{tabular}{lccc}
\hline Yogurt sample & $\mathrm{d} 1$ & $\mathrm{~d} 10$ & $\mathrm{~d} 20$ \\
\hline Water-holding capacity (\%) & $40.48 \pm 1.12^{\mathrm{a}, \mathrm{B}}$ & $37.32 \pm 1.23^{\mathrm{b}, \mathrm{C}}$ & $38.68 \pm 1.10^{\mathrm{ab}, \mathrm{C}}$ \\
CY & $42.34 \pm 3.19^{\mathrm{a}, \mathrm{B}}$ & $42.48 \pm 2.81^{\mathrm{a}, \mathrm{B}}$ & $45.75 \pm 0.84^{\mathrm{a}, \mathrm{B}}$ \\
T1 & $43.52 \pm 2.13^{\mathrm{a}, \mathrm{AB}}$ & $45.79 \pm 1.40^{\mathrm{a}, \mathrm{AB}}$ & $46.77 \pm 1.70^{\mathrm{a}, \mathrm{B}}$ \\
T2 & $43.75 \pm 2.73^{\mathrm{a}, \mathrm{AB}}$ & $44.59 \pm 2.94^{\mathrm{a}, \mathrm{AB}}$ & $46.58 \pm 2.48^{\mathrm{a}, \mathrm{B}}$ \\
T3 & $47.62 \pm 1.24^{\mathrm{a}, \mathrm{A}}$ & $47.28 \pm 2.49^{\mathrm{a}, \mathrm{A}}$ & $50.11 \pm 1.13^{\mathrm{a}, \mathrm{A}}$ \\
T4 & & & \\
Susceptibility to syneresis (\%) & $47.14 \pm 1.42^{\mathrm{a}, \mathrm{A}}$ & $45.71 \pm 1.01^{\mathrm{ab}, \mathrm{A}}$ & $52.85 \pm 3.77^{\mathrm{b}, \mathrm{A}}$ \\
CY & $40.41 \pm 2.94^{\mathrm{a}, \mathrm{B}}$ & $45.00 \pm 2.35^{\mathrm{a}, \mathrm{A}}$ & $42.08 \pm 2.94^{\mathrm{a}, \mathrm{B}}$ \\
T1 & $43.33 \pm 2.35^{\mathrm{a}, \mathrm{B}}$ & $40.83 \pm 4.71^{\mathrm{a}, \mathrm{A}}$ & $42.50 \pm 1.17^{\mathrm{a}, \mathrm{B}}$ \\
T2 & $39.16 \pm 1.17^{\mathrm{a}, \mathrm{B}}$ & $40.41 \pm 4.12^{\mathrm{a}, \mathrm{A}}$ & $42.50 \pm 1.17^{\mathrm{a}, \mathrm{B}}$ \\
T3 & $40.50 \pm 1.02^{\mathrm{a}, \mathrm{B}}$ & $40.00 \pm 0.80^{\mathrm{a}, \mathrm{A}}$ & $41.25 \pm 0.58^{\mathrm{a}, \mathrm{B}}$ \\
T4 & & & \\
pH & $4.67 \pm 0.01^{\mathrm{a}, \mathrm{B}}$ & $4.53 \pm 0.01^{\mathrm{b}, \mathrm{A}}$ & $4.30 \pm 0.14^{\mathrm{c}, \mathrm{A}}$ \\
CY & $4.83 \pm 0.13^{\mathrm{a}, \mathrm{A}}$ & $4.60 \pm 0.08^{\mathrm{ab}, \mathrm{A}}$ & $4.39 \pm 0.11^{\mathrm{b}, \mathrm{A}}$ \\
T1 & $4.77 \pm 0.05^{\mathrm{a}, \mathrm{AB}}$ & $4.59 \pm 0.08^{\mathrm{ab}, \mathrm{A}}$ & $4.39 \pm 0.09^{\mathrm{b}, \mathrm{A}}$ \\
T2 & $4.84 \pm 0.05^{\mathrm{a}, \mathrm{A}}$ & $4.57 \pm 0.07^{\mathrm{b}, \mathrm{A}}$ & $4.41 \pm 0.14^{\mathrm{b}, \mathrm{A}}$ \\
T3 & $4.75 \pm 0.07^{\mathrm{a}, \mathrm{AB}}$ & $4.58 \pm 0.12^{\mathrm{ab}, \mathrm{A}}$ & $4.43 \pm 0.12^{\mathrm{b}, \mathrm{A}}$ \\
T4 & & & \\
Titratable acidity (lactic acid \%) & $0.90 \pm 0.01^{\mathrm{a}, \mathrm{A}}$ & $0.95 \pm 0.02^{\mathrm{b}, \mathrm{B}}$ & $1.01 \pm 0.01^{\mathrm{c}, \mathrm{B}}$ \\
CY & $0.95 \pm 0.04^{\mathrm{a}, \mathrm{A}}$ & $1.22 \pm 0.03^{\mathrm{b}, \mathrm{A}}$ & $1.31 \pm 0.01^{\mathrm{c}, \mathrm{A}}$ \\
T1 & $0.95 \pm 0.04^{\mathrm{a}, \mathrm{A}}$ & $1.22 \pm 0.04^{\mathrm{b}, \mathrm{A}}$ & $1.32 \pm 0.02^{\mathrm{c}, \mathrm{A}}$ \\
T2 & $0.94 \pm 0.03^{\mathrm{a}, \mathrm{A}}$ & $1.21 \pm 0.02^{\mathrm{b}, \mathrm{A}}$ & $1.31 \pm 0.02^{\mathrm{c}, \mathrm{A}}$ \\
T3 & $0.95 \pm 0.03^{\mathrm{a}, \mathrm{A}}$ & $1.24 \pm 0.01^{\mathrm{b}, \mathrm{A}}$ & $1.30 \pm 0.01^{\mathrm{c}, \mathrm{A}}$ \\
T4 & & \\
\hline
\end{tabular}

${ }^{a-c}$ Means in a row followed by the same superscript are not significantly different by LSD test at the $5 \%$ level. ${ }^{\mathrm{A}-\mathrm{C}}$ Means in a column followed by the same superscript are not significantly different by LSD test at the $5 \%$ level.

${ }^{1} \mathrm{CY}=$ control yogurt; $\mathrm{T} 1=$ yogurt enriched with $4 \%$ SIS and $0 \%$ BGGL; T2 = yogurt enriched with $4 \%$ SIS and $0.5 \%$ BGGL; T3 = yogurt enriched with $4 \%$ SIS and $1.0 \%$ BGGL; T4 = yogurt enriched with $4 \%$ SIS and $1.5 \%$ BGGL. 
storage. Moreover, the WHC of the enriched samples significantly increased $(P<0.05)$ as the concentration of BGGL increased, independently of the storage time.

In agreement with the WHC results, STS was higher in the control samples than in the enriched yogurts. The STS of the control yogurt significantly increased $(P<0.05)$ during storage, but the effect of storage time was not significant $(P>0.05)$ for the enriched samples. Moreover, the STS tended to decrease as the concentration of BGGL increased, independently of storage time. This behavior could be attributable to the higher concentration of TS in the enriched yogurts as well as the presence of hydroxyl groups in the chemical structure of the BGGL, which may bind water by means of hydrogen bond interactions. Moreover, because the enriched yogurts contained additional proteins, different protein-water interactions and intrinsic protein factors (AA composition, protein conformation, and surface polarity or hydrophobicity) could have affected the STS (Isanga and Zhang, 2009). However, the obtained values of WHC and STS were similar to those previously found in yogurts fortified with dried nuts (OzturkogluBudak et al., 2016), $\beta$-glucan hydrocolloidal composite (Sahan et al., 2008), and peanut milk yogurt (Isanga and Zhang, 2009).

\section{Flow Behavior}

The flow behavior of the yogurt samples was modeled from shear rate sweep tests, and the data from flow curves were fitted to the power law model. The parameters obtained from this model are presented in Table 3. All yogurt samples showed a plastic-shear thinning behavior with flow index $(n)$ values lower than 1, ranging between 0.278 and 0.394 . Similar values have been found in commercial fermented milks from Colombia (Osorio et al., 2011). However, they were lower than those reported by Vasiljevic et al. (2007) for probiotic yogurts containing barley $\beta$-glucan. As observed, there were no significant differences $(P>0.05)$ in flow index values between the control samples and the enriched yogurts during the whole storage period.

The values of the consistency index $(K)$ obtained with the power law model ranged between 7.11 and $12.50 \mathrm{~Pa} \cdot \mathrm{s}^{n}$. Values within this range have been found in fat-free yogurts with and without addition of milk solids nonfat ( $\mathrm{Yu}$ et al., 2016). The enriched samples showed lower $K$ values $(P<0.05)$ than the control yogurts and the consistency index displayed an increasing trend throughout the refrigerated storage. However, it is worth mentioning that the stirring and the removal of the SIS for analyses could have induced some structural changes in the gel matrix, which could have affected the flow properties and the consistency of the enriched yogurt samples (Lee and Lucey, 2010).

\section{Textural Parameters}

The determination of the textural parameters of foods is important to simulate their breakdown as it occurs in the mouth or during processing, and sometimes they are correlated with the sensory textural attributes of the product (Hickisch et al., 2016). The textural characteristics of fermented milks such as yogurt are affected by their composition, manufacturing processes, and starter culture because these factors may influence the arrangement of the network gel.

The results of firmness, consistency, cohesiveness, and index of viscosity are summarized in Table 3. In agreement with the results of the flow behavior, it can be noticed that all the textural parameters of the control samples were significantly higher $(P<0.05)$ than those found in the enriched yogurts during the whole storage period, which indicates that the control samples presented a stronger gel structure. These results may be attributed to the presence of the small particles of SIS as well as to the long chain of polysaccharide of the BGGL into the enriched samples, which may have interfered with the development of the 3-dimensional structure of caseins, leading to weaker gels (Vasiljevic et al., 2007). However, it can be observed that the concentration of BGGL did not affect $(P>0.05)$ the textural parameters of the enriched yogurt samples during refrigerated storage.

The firmness values of the yogurt samples varied between 42.24 and $68.55 \mathrm{~g}_{\mathrm{f}}$ and showed an increasing trend during storage, which was statistically significant $(P<0.05)$ for the enriched yogurts. These results are comparable with those obtained by Singh et al. (2012) for yogurts with oat $\beta$-glucan added and by OzturkogluBudak et al. (2016) for yogurts fortified with different types of nuts.

The consistency and the index of viscosity are related parameters. Consistency indicates the thickness of the sample, whereas the index of viscosity gauges the resistance of the sample to flow off the disc during back extrusion (Ciron et al., 2010). The consistency of the control samples increased from about 1,650 to 1,810 $\mathrm{g}_{\mathrm{f}} \mathrm{s}$ after $20 \mathrm{~d}$ of storage, whereas it varied from about 1,050 to $1,300 \mathrm{~g}_{\mathrm{f}} \cdot \mathrm{s}$ for the enriched yogurts. As for the index of viscosity, it can be observed that the increasing rate during storage was higher in the enriched yogurts than in the control samples, which could be attributed to the water binding ability of BGGL in these samples. A similar behavior was found for cohesiveness, which varied from about 88 to $97 \mathrm{~g}_{\mathrm{f}}$ and between 39 and 62 
$\mathrm{g}_{\mathrm{f}}$ for the control and enriched yogurt samples, respectively.

\section{Postacidification Behavior}

Table 2 presents the $\mathrm{pH}$ and TA values of the yogurt samples during storage at $4 \pm 1^{\circ} \mathrm{C}$. As normally observed during storage of the fermented milk products, the $\mathrm{pH}$ values of all yogurt samples slightly decreased $(P<0.05)$ during refrigerated storage, independent of the level of BGGL addition, due to the production of lactic acid by the starter culture. However, there were no significant differences $(P>0.05)$ in the $\mathrm{pH}$ values between the enriched yogurts and the control sample on $\mathrm{d} 10$ and 20 . The higher $\mathrm{pH}$ values observed on $\mathrm{d}$
1 could be attributable to an increase in the buffering capacity as a result of the additional proteins from SIS and BGGL present in the system (Ozturkoglu-Budak et al., 2016). Moreover, the polysaccharide addition could have slowed the acidification, as has been indicated in previous studies (Lazaridou et al., 2014).

The TA of all yogurt samples significantly increased $(P<0.05)$ during refrigerated storage independent of the level of BGGL addition. It can be observed that the enriched samples showed higher values of lactic acid than the control samples $(P<0.05)$ throughout storage, probably because they contains higher concentrations of carbohydrates, which could have served as additional substrate for the starter culture, or because of the contribution of AA from both ingredients (SIS

Table 3. Textural and flow parameters of yogurts enriched with sacha inchi seeds (SIS) and $\beta$-glucans from Ganoderma lucidum (BGGL) during storage

\begin{tabular}{|c|c|c|c|}
\hline Yogurt sample & d 1 & d 10 & d 20 \\
\hline \multicolumn{4}{|l|}{ Firmness $\left(g_{f}\right)$} \\
\hline CY & $65.58 \pm 1.89^{\mathrm{a}, \mathrm{A}}$ & $65.94 \pm 0.71^{\mathrm{a}, \mathrm{A}}$ & $68.55 \pm 1.75^{\mathrm{a}, \mathrm{A}}$ \\
\hline $\mathrm{T} 1$ & $45.02 \pm 0.91^{\mathrm{a}, \mathrm{B}}$ & $50.41 \pm 2.73^{\mathrm{b}, \mathrm{BC}}$ & $55.32 \pm 2.62^{\mathrm{b}, \mathrm{B}}$ \\
\hline $\mathrm{T} 2$ & $43.47 \pm 3.97^{\mathrm{a}, \mathrm{B}}$ & $50.82 \pm 2.68^{\mathrm{ab}, \mathrm{BC}}$ & $52.35 \pm 5.73^{\mathrm{b}, \mathrm{B}}$ \\
\hline T3 & $46.09 \pm 0.40^{\mathrm{a}, \mathrm{B}}$ & $46.63 \pm 3.77^{\mathrm{a}, \mathrm{C}}$ & $50.09 \pm 3.40^{\mathrm{a}, \mathrm{B}}$ \\
\hline $\mathrm{T} 4$ & $42.24 \pm 3.70^{\mathrm{a}, \mathrm{B}}$ & $51.97 \pm 4.36^{\mathrm{ab}, \mathrm{B}}$ & $56.80 \pm 4.72^{\mathrm{b}, \mathrm{B}}$ \\
\hline \multicolumn{4}{|c|}{ Consistency $\left(g_{f} \times s\right)$} \\
\hline $\mathrm{CY}$ & $1,652.68 \pm 58.65^{\mathrm{a}, \mathrm{A}}$ & $1,604.52 \pm 56.61^{\mathrm{a}, \mathrm{A}}$ & $1,812.99 \pm 53.46^{\mathrm{b}, \mathrm{A}}$ \\
\hline $\mathrm{T} 1$ & $1,070.83 \pm 64.11^{\mathrm{a}, \mathrm{B}}$ & $1,220.59 \pm 149.86^{\mathrm{ab}, \mathrm{B}}$ & $1,333.71 \pm 62.85^{\mathrm{b}, \mathrm{B}}$ \\
\hline $\mathrm{T} 2$ & $1,053.18 \pm 108.46^{\mathrm{a}, \mathrm{B}}$ & $1,270.14 \pm 94.61^{\mathrm{a}, \mathrm{B}}$ & $1,276.68 \pm 137.42^{\mathrm{a}, \mathrm{B}}$ \\
\hline T3 & $1,017.43 \pm 167.21^{\mathrm{a}, \mathrm{B}}$ & $1,132.59 \pm 214.31^{\mathrm{a}, \mathrm{B}}$ & $1,212.41 \pm 102.26^{\mathrm{a}, \mathrm{B}}$ \\
\hline $\mathrm{T} 4$ & $1,025.90 \pm 122.21^{\mathrm{a}, \mathrm{B}}$ & $1,289.70 \pm 127.27^{\mathrm{ab}, \mathrm{B}}$ & $1,363.38 \pm 113.72^{\mathrm{b}, \mathrm{E}}$ \\
\hline \multicolumn{4}{|c|}{ Cohesiveness $\left(\mathrm{g}_{\mathrm{f}}\right)$} \\
\hline $\mathrm{CY}$ & $-87.87 \pm 5.55^{\mathrm{a}, \mathrm{B}}$ & $-88.80 \pm 6.60^{\mathrm{a}, \mathrm{B}}$ & $-96.95 \pm 2.45^{\mathrm{a}, \mathrm{C}}$ \\
\hline T1 & $-45.46 \pm 4.45^{\mathrm{a}, \mathrm{A}}$ & $-47.34 \pm 4.98^{\mathrm{a}, \mathrm{A}}$ & $-60.31 \pm 5.25^{\mathrm{b}, \mathrm{AB}}$ \\
\hline $\mathrm{T} 2$ & $-39.98 \pm 5.39^{\mathrm{a}, \mathrm{A}}$ & $-51.37 \pm 3.04^{\mathrm{a}, \mathrm{A}}$ & $-55.10 \pm 4.40^{\mathrm{b}, \mathrm{AB}}$ \\
\hline T3 & $-41.58 \pm 3.16^{\mathrm{a}, \mathrm{A}}$ & $-44.22 \pm 12.66^{\mathrm{a}, \mathrm{A}}$ & $-46.20 \pm 5.22^{\mathrm{a}, \mathrm{A}}$ \\
\hline $\mathrm{T} 4$ & $-39.02 \pm 6.01^{\mathrm{a}, \mathrm{A}}$ & $-52.37 \pm 4.94^{\mathrm{ab}, \mathrm{A}}$ & $-61.80 \pm 5.31^{\mathrm{b}, \mathrm{B}}$ \\
\hline \multicolumn{4}{|c|}{ Index of viscosity $\left(g_{f} \times s\right)$} \\
\hline $\mathrm{CY}$ & $-227.08 \pm 28.01^{\mathrm{a}, \mathrm{B}}$ & $-214.72 \pm 10.70^{\mathrm{a}, \mathrm{B}}$ & $-222.10 \pm 9.14^{\mathrm{a}, \mathrm{C}}$ \\
\hline T1 & $-103.98 \pm 3.64^{\mathrm{a}, \mathrm{A}}$ & $-118.76 \pm 19.03^{\mathrm{ab}, \mathrm{A}}$ & $-135.73 \pm 3.86^{\mathrm{b}, \mathrm{B}}$ \\
\hline $\mathrm{T} 2$ & $-96.98 \pm 13.24^{\mathrm{a}, \mathrm{A}}$ & $-129.21 \pm 6.00^{\mathrm{a}, \mathrm{A}}$ & $-125.36 \pm 22.39^{\mathrm{a}, \mathrm{AB}}$ \\
\hline T3 & $-93.29 \pm 16.50^{\mathrm{a}, \mathrm{A}}$ & $-108.95 \pm 25.59^{\mathrm{a}, \mathrm{A}}$ & $-112.22 \pm 14.04^{\mathrm{a}, \mathrm{A}}$ \\
\hline $\mathrm{T} 4$ & $-91.85 \pm 15.83^{\mathrm{a}, \mathrm{A}}$ & $128.76 \pm 12.17^{\mathrm{b}, \mathrm{A}}$ & $-136.70 \pm 12.22^{\mathrm{b}, \mathrm{B}}$ \\
\hline \multicolumn{4}{|c|}{ Consistency index } \\
\hline $\mathrm{CY}$ & $10.69 \pm 1.00^{\mathrm{a}, \mathrm{A}}$ & $10.69 \pm 1.94^{\mathrm{a}, \mathrm{A}}$ & $12.50 \pm 1.99^{\mathrm{a}, \mathrm{A}}$ \\
\hline $\mathrm{T} 1$ & $8.22 \pm 0.12^{\mathrm{a}, \mathrm{B}}$ & $7.70 \pm 0.43^{\mathrm{a}, \mathrm{B}}$ & $7.56 \pm 0.62^{\mathrm{a}, \mathrm{B}}$ \\
\hline $\mathrm{T} 2$ & $7.70 \pm 0.63^{\mathrm{a}, \mathrm{B}}$ & $8.72 \pm 0.77^{\mathrm{a}, \mathrm{AB}}$ & $8.92 \pm 0.47^{\mathrm{a}, \mathrm{B}}$ \\
\hline T3 & $7.78 \pm 0.41^{\mathrm{a}, \mathrm{B}}$ & $9.88 \pm 1.66^{\mathrm{b}, \mathrm{AB}}$ & $7.11 \pm 0.55^{\mathrm{a}, \mathrm{B}}$ \\
\hline $\mathrm{T} 4$ & $7.81 \pm 0.41^{\mathrm{a}, \mathrm{B}}$ & $8.36 \pm 1.78^{\mathrm{a}, \mathrm{AB}}$ & $9.51 \pm 2.02^{\mathrm{a}, \mathrm{B}}$ \\
\hline \multicolumn{4}{|l|}{ Flow index } \\
\hline $\mathrm{CY}$ & $0.351 \pm 0.019^{\mathrm{a}, \mathrm{A}}$ & $0.328 \pm 0.068^{\mathrm{a}, \mathrm{A}}$ & $0.278 \pm 0.022^{\mathrm{a}, \mathrm{B}}$ \\
\hline $\mathrm{T} 1$ & $0.326 \pm 0.029^{\mathrm{a}, \mathrm{A}}$ & $0.328 \pm 0.066^{\mathrm{a}, \mathrm{A}}$ & $0.337 \pm 0.082^{\mathrm{a}, \mathrm{AB}}$ \\
\hline $\mathrm{T} 2$ & $0.332 \pm 0.032^{\mathrm{a}, \mathrm{A}}$ & $0.314 \pm 0.036^{\mathrm{a}, \mathrm{A}}$ & $0.315 \pm 0.062^{\mathrm{a}, \mathrm{AB}}$ \\
\hline T3 & $0.336 \pm 0.001^{\mathrm{a}, \mathrm{A}}$ & $0.298 \pm 0.017^{\mathrm{b}, \mathrm{A}}$ & $0.394 \pm 0.016^{\mathrm{c}, \mathrm{A}}$ \\
\hline $\mathrm{T} 4$ & $0.327 \pm 0.040^{\mathrm{a}, \mathrm{A}}$ & $0.317 \pm 0.032^{\mathrm{ab}, \mathrm{A}}$ & $0.306 \pm 0.042^{\mathrm{b}, \mathrm{B}}$ \\
\hline
\end{tabular}

${ }^{a-c}$ Means in a row followed by the same superscript are not significantly different by LSD test at the $5 \%$ level. ${ }^{\mathrm{A}-\mathrm{C}}$ Means in a column followed by the same superscript are not significantly different by LSD test at the $5 \%$ level.

${ }^{1} \mathrm{CY}=$ control yogurt; $\mathrm{T} 1=$ yogurt enriched with $4 \%$ SIS and $0 \%$ BGGL; T2 = yogurt enriched with $4 \%$ SIS and $0.5 \%$ BGGL; T3 = yogurt enriched with $4 \%$ SIS and $1.0 \%$ BGGL; T4 = yogurt enriched with $4 \%$ SIS and $1.5 \%$ BGGL. 
and BGGL). A similar behavior was reported in yogurts fortified with dried nuts (Ozturkoglu-Budak et al., 2016) as well as in yogurts with added $\beta$-glucan composite (Sahan et al., 2008).

\section{Sensory Analysis}

Figure 4 shows the average results of the consumer acceptance of the control and enriched yogurt samples. As can be observed, all the yogurt samples presented levels of acceptance higher than $70 \%$, and there were no significant negative ratings for the enriched samples. The highest score was obtained for the control yogurt (93.3\%), followed by the treatments T3 $(88.7 \%)$, T4 (84.9\%), T2 $(83.0 \%)$, and $\mathrm{T} 1(71.7 \%)$. These results indicate that the addition of BGGL helps improve the sensorial acceptance of yogurts enriched only with SIS.

\section{AA Composition}

To determine the influence of the added ingredients (SIS and BGGL) on the AA composition of the yogurt samples, 4 new yogurts were produced, taking into account the obtained results of the sensory analysis: 1 control yogurt, 1 yogurt containing $4 \%$ (wt/wt) SIS (SIY 4\%), 1 yogurt containing 4\% (wt/wt) SIS and 1\% BGGL (SIBGY 4-1\%), and 1 yogurt containing 1\% BGGL (BGY 1\%). As can be observed in Figure 5 , all yogurt samples contained almost all the EAA and NEAA in varying amounts. However, the samples enriched with SIS displayed significantly $(P<0.05)$ higher amounts of aspartic acid, serine, arginine, glycine, threonine, tyrosine, and alanine, whereas the contents of the other AA evaluated were slightly higher, excepting for methionine, which was significantly lower $(P<0.05 ; \sim 33.0$ vs. $34.8 \mathrm{mg} / \mathrm{g}$ of protein $)$. All yogurt samples met the recommendations of the FAO/WHO/ UNU (1985) scoring pattern developed for preschool children 2 to $5 \mathrm{yr}$ of age except for threonine, and it is worth mentioning that the enrichment with SIS allowed meeting the requirements for this EAA. These results were expected because SIS are considered a good source of well-balanced protein, comparable with soy protein in content of total EAA (Hamaker et al., 1992).

\section{ACE-Inhibitory Activity}

Fermented milk products have shown important antihypertensive effects because some bioactive peptides encrypted within dairy proteins are released during the milk fermentation with lactic acid bacteria (BeltránBarrientos et al., 2016). These peptides are able to

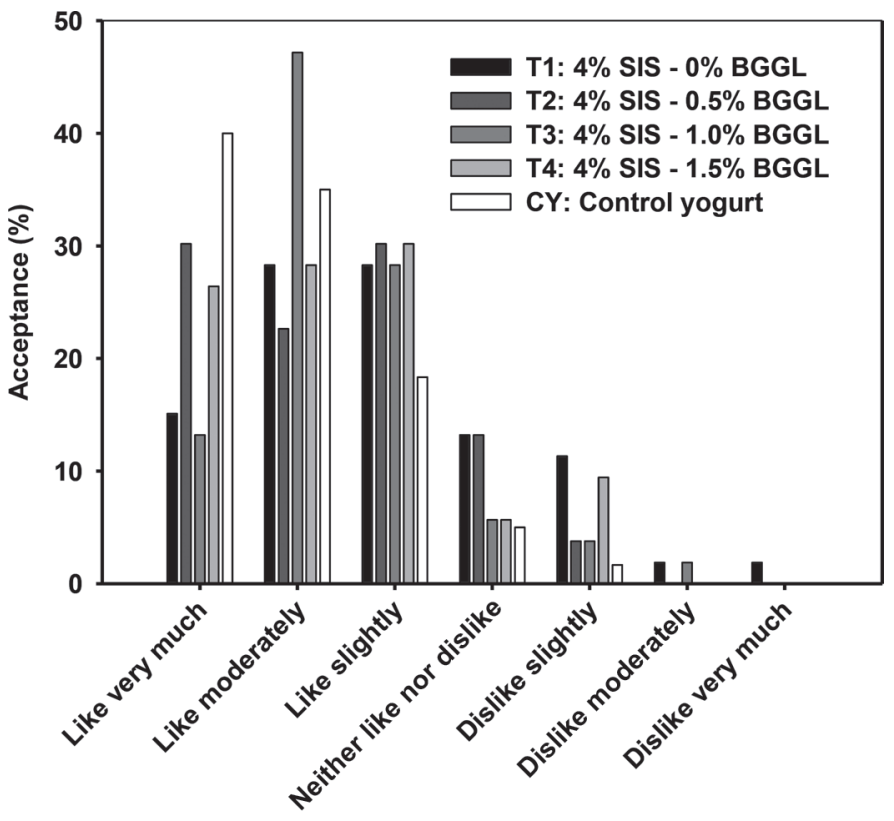

Figure 4. Sensory acceptance of yogurts enriched with sacha inchi seeds (SIS) and $\beta$-glucans from Ganoderma lucidum (BGGL).

inhibit the activity of the angiotensin I-converting enzyme, avoiding the conversion of angiotensin I into angiotensin II, which causes vasoconstriction leading to increased blood pressure (Puchalska et al., 2015). The in vitro ACE-inhibitory activity of some selected yogurt samples produced in this study is presented in

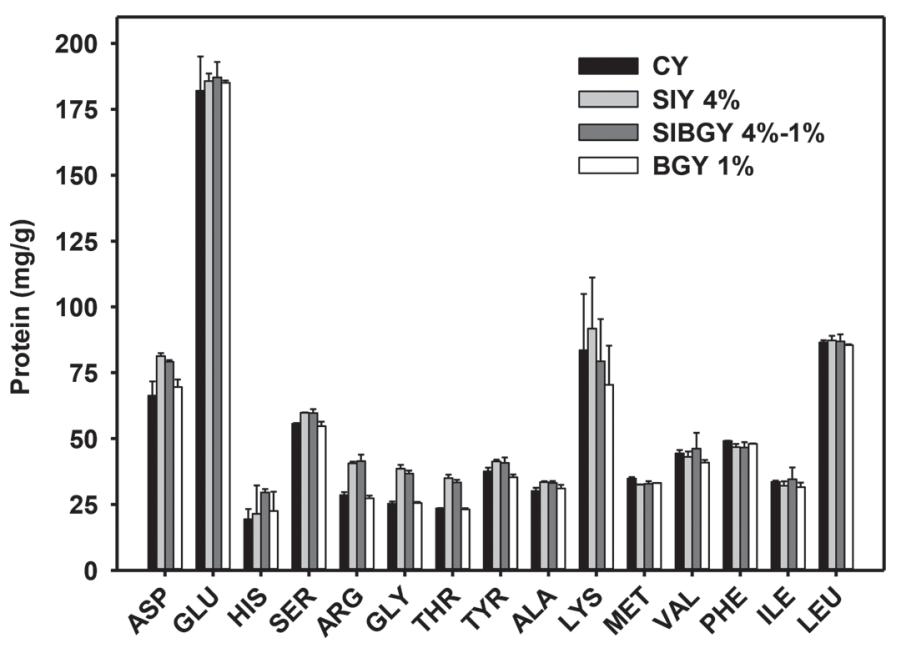

Figure 5. Amino acid profile of yogurts enriched with sacha inchi seeds (SIS) and $\beta$-glucans from Ganoderma lucidum (BGGL). CY $=$ control yogurt; SIY $4 \%=$ yogurt enriched with $4 \%$ SIS; SIBGY $4 \%-1 \%=$ yogurt enriched with $4 \%$ SIS and $1.0 \%$ BGGL; BGY $1 \%=$ yogurt enriched with 1.0\% BGGL. Error bars indicate SD. 
Table 4. As can be observed, the yogurt samples evaluated showed ACE-inhibitory activity between 35.93 and $58.93 \%$. These values were within the range reported by Hernández-Ledesma et al. (2003) for commercial skim and full-fat yogurts. Nevertheless, they were lower than those obtained in yogurts fermented by $L$. delbrueckii ssp. bulgaricus Lb1466, S. thermophilus St1342, L. acidophilus L10, Lactobacillus casei L26, and B. lactis B94; Donkor et al., 2007). As can be noticed in Table 4, the ACE-inhibitory activity of the yogurt samples enriched with SIS and BGGL was significantly higher $(P<0.05)$ than that of the control yogurt. Moreover, the highest value of ACE-inhibitory activity (58.93\%) was displayed by the yogurt sample containing both SIS and BGGL. These results suggest that both ingredients could have contributed to enhance the ACEinhibitory activity of the yogurt samples. On one hand, the protein of the SIS could be a precursor of bioactive peptides with ACE-inhibitory activity, and on the other hand, the triterpenoids present in the Ganoderma lucidum could act as inhibitors of the ACE, as found in previous studies (Boh et al., 2007). Furthermore, it has been found that yogurts containing $\beta$-glucan and pectin showed faster proteolysis and lower release of large peptides, which could contribute to their antihypertensive activity (Rinaldi et al., 2015). However, more research is needed to identify the compounds responsible for the ACE-inhibitory activity in the yogurts enriched with SIS and BGGL.

\section{CONCLUSIONS}

In this study, yogurts produced from skim milk powder were enriched with 2 natural ingredients (SIS and commercial BGGL), and their physicochemical and sensory acceptance was determined. The obtained results indicated that the addition of both ingredients did not significantly affect the fermentation kinetics because after about $5 \mathrm{~h}$ all samples reached a $\mathrm{pH}$ value of 4.6. The proximate composition of the enriched samples was significantly improved by the inclusion of SIS and BGGL in comparison with the control samples. The concentration of protein and carbohydrates of the enriched yogurts increased up to 23 and $17 \%$, respectively, whereas their fat content was about 17-fold higher than that of the control yogurts. The enriched yogurts were of high nutritional value because they contained high amounts of PUFA ( $~ 50 \%$ ALA and 32\% LA) and displayed a very low IA (0.06). Moreover, the low ratio of LA/ALA $(\sim 0.66)$ showed by the enriched yogurts is desirable for reducing the risk of various chronic diseases, such as cardiovascular disease, cancer, and inflammatory and autoimmune diseases. Although significant differences
Table 4. Angiotensin-converting enzyme inhibitory (ACE-I) activity of yogurts enriched with sacha inchi seeds (SIS) and $\beta$-glucans from Ganoderma lucidum (BGGL) ${ }^{1}$

\begin{tabular}{lc}
\hline Yogurt sample & ACE-I activity $(\%)$ \\
\hline CY $4 \%$ & $35.93 \pm 3.70^{\mathrm{a}}$ \\
SIY 4\% & $50.82 \pm 10.76^{\mathrm{b}}$ \\
SIBGY 4\%-1\% & $58.93 \pm 11.68^{\mathrm{b}}$ \\
BGY $1 \%$ & $57.09 \pm 9.43^{\mathrm{b}}$ \\
\hline
\end{tabular}

$\overline{\mathrm{a}, \mathrm{b}}$ Means in a column followed by the same superscript are not significantly different by LSD test at the $5 \%$ level.

${ }^{1} \mathrm{CY}=$ control yogurt; SIY $4 \%=$ yogurt enriched with $4 \%$ SIS; SIBGY $4 \%-1 \%=$ yogurt enriched with $4 \%$ SIS and $1.0 \%$ BGGL; BGY $1 \%=$ yogurt enriched with 1.0\% BGGL.

were found in the textural parameters of the enriched yogurts in comparison with the control samples, they showed high sensory acceptance $(>70 \%)$. The control samples displayed the highest sensorial score (93.3\%), but the yogurts containing 4\% SIS and 1\% BGGL were also well accepted by untrained panelists $(88.7 \%$ acceptance). Moreover, the ACE-inhibitory activity of the enriched yogurts was significantly higher in comparison with the control samples (50.8-58.9 vs. $35.9 \%)$. The results obtained in this study could be used for the development of yogurts enriched with natural ingredients, which are products in high demand according to the current consumer trends.

\section{ACKNOWLEDGMENTS}

This research was funded by the Universidad Nacional de Colombia, Corpoica, Gobernación de Cundinamarca and Alcaldía Mayor de Bogotá D.C, within the project "Corredor tecnológico agroindustrial Bogotá y Cundinamarca Derivado 2." The authors acknowledge Blanca Hernández-Ledesma for her technical assistance in the analyses of angiotensin-converting enzyme-inhibitory activity.

\section{REFERENCES}

AOAC International. 2012. Official Methods of Analysis. 19th ed. AOAC International, Gaithersburg, MD.

Beltrán-Barrientos, L. M., A. Hernández-Mendoza, M. J. TorresLlanez, A. F. González-Córdova, and B. Vallejo-Córdoba. 2016. Invited review: Fermented milk as antihypertensive functional food. J. Dairy Sci. 99:4099-4110.

Bishop, K. S., C. H. J. Kao, Y. Xu, M. P. Glucina, R. R. M. Paterson, and L. R. Ferguson. 2015. From 2000 years of Ganoderma lucidum to recent developments in nutraceuticals. Phytochemistry 114:56-65.

Boh, B., M. Berovic, J. Zhang, and L. Zhi-Bin. 2007. Ganoderma lucidum and its pharmaceutically active compounds. Pages 265-301 in Biotechnology Annual Review. Vol. 13. M. R. El-Gewely, ed. Elsevier, Amsterdam, the Netherlands.

Boye, J. I. 2015. Nutraceutical and Functional Food Processing Technology. Wiley, Hoboken, NJ. 
Chee, C. P., J. J. Gallaher, D. Djordjevic, H. Faraji, D. J. McClements, E. A. Decker, R. Hollender, D. G. Peterson, R. F. Roberts, and J. N. Coupland. 2005. Chemical and sensory analysis of strawberry flavoured yogurt supplemented with an algae oil emulsion. J. Dairy Res. 72:311-316.

Chirinos, R., G. Zuloeta, R. Pedreschi, E. Mignolet, Y. Larondelle, and D. Campos. 2013. Sacha inchi (Plukenetia volubilis): A seed source of polyunsaturated fatty acids, tocopherols, phytosterols, phenolic compounds and antioxidant capacity. Food Chem. 141:1732-1739.

Ciron, C. I. E., V. L. Gee, A. L. Kelly, and M. A. E. Auty. 2010. Comparison of the effects of high-pressure microfluidization and conventional homogenization of milk on particle size, water retention and texture of non-fat and low-fat yoghurts. Int. Dairy J. 20:314-320.

Dal Bello, B., L. Torri, M. Piochi, and G. Zeppa. 2015. Healthy yogurt fortified with n-3 fatty acids from vegetable sources. J. Dairy Sci. 98:8375-8385.

do Espírito Santo, A. P., N. S. Cartolano, T. F. Silva, F. A. S. M. Soares, L. A. Gioielli, P. Perego, A. Converti, and M. N. Oliveira. 2012. Fibers from fruit by-products enhance probiotic viability and fatty acid profile and increase CLA content in yoghurts. Int. J. Food Microbiol. 154:135-144.

do Espírito Santo, A. P., R. C. Silva, F. A. S. M. Soares, D. Anjos, L. A. Gioielli, and M. N. Oliveira. 2010. Açai pulp addition improves fatty acid profile and probiotic viability in yoghurt. Int. Dairy J. $20: 415-422$.

Dong, Q., Y. Wang, L. Shi, J. Yao, J. Li, F. Ma, and K. Ding. 2012. A novel water-soluble $\beta$-D-glucan isolated from the spores of Ganoderma lucidum. Carbohydr. Res. 353:100-105.

Donkor, O. N., A. Henriksson, T. K. Singh, T. Vasiljevic, and N. P. Shah. 2007. ACE-inhibitory activity of probiotic yoghurt. Int. Dairy J. 17:1321-1331.

FAO/WHO/ONU (Food and Agriculture Organization of the United Nations/World Health Organization/Organização das Nações Unidas para Agricultura e Alimentação. 1985. Joint FAO/WHO/ONU expert consultation: Energy and protein requirements. WHO Tech. Rep. Ser. No. 274. World Health Organization, Geneva, Switzerland.

Gee, V. L., T. Vasanthan, and F. Temelli. 2007. Viscosity of model yogurt systems enriched with barley $\beta$-glucan as influenced by starter cultures. Int. Dairy J. 17:1083-1088.

Gutiérrez, L.-F., and K. Belkacemi. 2008. Palmitoleic acid enrichment of seabuckthorn (Hippophae rhamnoides L.) pulp oil by crystallization process. Sep. Sci. Technol. 43:2003-2022.

Gutiérrez, L.-F., S. Hamoudi, and K. Belkacemi. 2012. Effective gold catalyst supported on mesoporous silica decorated by ceria for the synthesis of high value lactobionic acid. Appl. Catal. A Gen. 425-426:213-223.

Gutiérrez, L.-F., L. M. Rosada, and A. Jimenez. 2011. Chemical composition of Sacha Inchi (Plukenetia volubilis L.) seeds and characteristics of their lipid fraction. Grasas Aceites 62:76-83.

Hamaker, B. R., C. Valles, R. Gilman, R. M. Hardmeier, D. Clark, H. H. Garcia, A. E. Gonzales, I. Kohlstad, M. Castro, R. Valdivia, T. Rodriguez, and M. Lescano. 1992. Amino acid and fatty acid profiles of the Inca peanut (Plukenetia volubilis). Cereal Chem. 69:461-463.

Harte, F., L. Luedecke, B. Swanson, and G. V. Barbosa-Cánovas. 2003. Low-fat set yogurt made from milk subjected to combinations of high hydrostatic pressure and thermal processing. J. Dairy Sci. 86:1074-1082.

Hernández-Ledesma, B., P. J. Martín-Álvarez, and E. Pueyo. 2003. Assessment of the spectrophotometric method for determination of angiotensin-converting-enzyme activity: Influence of the inhibition type. J. Agric. Food Chem. 51:4175-4179.

Hickisch, A., R. Beer, R. F. Vogel, and S. Toelstede. 2016. Influence of lupin-based milk alternative heat treatment and exopolysaccharide-producing lactic acid bacteria on the physical characteristics of lupin-based yogurt alternatives. Food Res. Int. 84:180-188.

Huang, S.-Q., J.-W. Li, Y.-Q. Li, and Z. Wang. 2011. Purification and structural characterization of a new water-soluble neutral polysac- charide GLP-F1-1 from Ganoderma lucidum. Int. J. Biol. Macromol. 48:165-169.

Isanga, J., and G. Zhang. 2009. Production and evaluation of some physicochemical parameters of peanut milk yoghurt. Lebensm. Wiss. Technol. 42:1132-1138.

Jajić, I., S. Krstović, D. Glamočić, S. Jakšić, and B. Abramović. 2013. Validation of an HPLC method for the determination of amino acids in feed. J. Serbian Chem. Soc. 78:839-850.

James, C. S. 1995. Analytical Chemistry of Foods. Springer, New York, NY.

Kan, Y., T. Chen, Y. Wu, J. Wu, and J. Wu. 2015. Antioxidant activity of polysaccharide extracted from Ganoderma lucidum using response surface methodology. Int. J. Biol. Macromol. 72:151-157.

Kozarski, M., A. Klaus, M. Nikšić, M. M. Vrvić, N. Todorović, D. Jakovljević, and L. J. L. D. Van Griensven. 2012. Antioxidative activities and chemical characterization of polysaccharide extracts from the widely used mushrooms Ganoderma applanatum, Ganoderma lucidum, Lentinus edodes and Trametes versicolor. J. Food Compos. Anal. 26:144-153.

Kumar, H. 2010. Development and evaluation of a beta-glucan biopolymer formulation of lactoferrin produced using a novel cryomilling technique. PhD Diss. The University of Auckland, New Zealand.

Lane, K. E., W. Li, C. Smith, and E. Derbyshire. 2014. The bioavailability of an omega-3-rich algal oil is improved by nanoemulsion technology using yogurt as a food vehicle. Int. J. Food Sci. Technol. 49:1264-1271.

Lazaridou, A., A. Serafeimidou, C. G. Biliaderis, T. Moschakis, and N. Tzanetakis. 2014. Structure development and acidification kinetics in fermented milk containing oat $\beta$-glucan, a yogurt culture and a probiotic strain. Food Hydrocoll. 39:204-214.

Lee, W. J., and J. A. Lucey. 2010. Formation and physical properties of yogurt. Asian-australas. J. Anim. Sci. 23:1127-1136.

Martín-Diana, A. B., C. Janer, C. Peláez, and T. Requena. 2004. Effect of milk fat replacement by polyunsaturated fatty acids on the microbiological, rheological and sensorial properties of fermented milks. J. Sci. Food Agric. 84:1599-1605.

Meilgaard, M. C., B. T. Carr, and G. V. Civille. 2006. Sensory Evaluation Techniques. 4th ed. CRC Press, Boca Raton, FL.

Merkle, R. K., and I. Poppe. 1994. Carbohydrate composition analysis of glycoconjugates by gas-liquid chromatography/mass spectrometry. Pages 1-15 in Methods in Enzymology. Vol. 230. J. K. Lennarz and G. W. Hart, ed. Academic Press, Cambridge, MA.

Osorio, J. A., C. Ramirez, C. F. Novoa, and L.-F. Gutiérrez. 2011. Conjugated linoleic acid, fatty acid profile and process properties in kumis - Fermented milk consumed in Colombia. Vitae-Revista de la Facultad de Quimica Farmaceutica 18:144-152.

Özer, B. H., and H. A. Kirmaci. 2010. Functional milks and dairy beverages. Int. J. Dairy Technol. 63:1-15.

Ozturkoglu-Budak, S., C. Akal, and A. Yetisemiyen. 2016. Effect of dried nut fortification on functional, physicochemical, textural, and microbiological properties of yogurt. J. Dairy Sci. 99:8511-8523.

Puchalska, P., M. L. Marina Alegre, and M. C. García López. 2015. Isolation and characterization of peptides with antihypertensive activity in foodstuffs. Crit. Rev. Food Sci. Nutr. 55:521-551.

Rinaldi, L., L.-E. Rioux, M. Britten, and S. L. Turgeon. 2015. In vitro bioaccessibility of peptides and amino acids from yogurt made with starch, pectin, or $\beta$-glucan. Int. Dairy J. 46:39-45.

Sabeena Farvin, K. H., C. P. Baron, N. S. Nielsen, and C. Jacobsen. 2010. Antioxidant activity of yoghurt peptides: Part 1-In vitro assays and evaluation in $\omega-3$ enriched milk. Food Chem. 123:10811089

Sahan, N., K. Yasar, and A. A. Hayaloglu. 2008. Physical, chemical and flavour quality of non-fat yogurt as affected by a $\beta$-glucan hydrocolloidal composite during storage. Food Hydrocoll. 22:12911297.

Sanchez-Reinoso, Z., and L.-F. Gutiérrez. 2017. Effects of the emulsion composition on the physical properties and oxidative stability of sacha inchi (Plukenetia volubilis L.) oil microcapsules produced by spray drying. Food Bioproc. Techol. 10:1354-1366. 
Sharafbafi, N., M. Alexander, S. M. Tosh, and M. Corredig. 2015. Dynamics of phase separation in oat $\beta$-glucan/milk mixtures studied with ultrasonic and diffusing wave spectroscopy. Food Biophys. 10:66-75.

Simopoulos, A. P. 2002. The importance of the ratio of omega-6/ omega-3 essential fatty acids. Biomed. Pharmacother. 56:365-379.

Singh, M., S. Kim, and S. X. Liu. 2012. Effect of purified oat $\beta$-glucan on fermentation of set-style yogurt mix. J. Food Sci. 77:E195E201.

Tamjidi, F., A. Nasirpour, and M. Shahedi. 2012. Physicochemical and sensory properties of yogurt enriched with microencapsulated fish oil. Food Sci. Technol. Int. 18:381-390.

Vasiljevic, T., T. Kealy, and V. K. Mishra. 2007. Effects of $\beta$-glucan addition to a probiotic containing yogurt. J. Food Sci. 72:C405C411.
Williams, E. B., B. Hooper, A. Spiro, and S. Stanner. 2015. The contribution of yogurt to nutrient intakes across the life course. Nutr. Bull. 40:9-32.

York, W. S., A. G. Darvill, M. McNeil, T. T. Stevenson, and P. Albersheim. 1985. Isolation and characterization of plant cell walls and cell-wall components. Methods Enzymol. 118:3-40.

Yu, H.-Y., L. Wang, and K. L. McCarthy. 2016. Characterization of yogurts made with milk solids nonfat by rheological behavior and nuclear magnetic resonance spectroscopy. J. Food Drug Anal. 24:804-812.

Zhu, F., B. Du, and B. Xu. 2016. A critical review on production and industrial applications of beta-glucans. Food Hydrocoll. 52:275288 